\title{
微生物特別是細菌分类中的几个問題
}

閻逊初

微生物分类的目的, 在于訩識各种微观 的生物个体，手了解它們彼此之間的关系。

由于微生物分类学发展較晚, 所以一开 始就采用了林奈对于植物的分类法, 郎把各 类微生物都分为种、属、科、目、綱、門等 各級的分类单位。同时也采納了他的双重命 名法: 以属名为主, 使用形容詞区別种。后 来入根据較小的差別在种內細分为变种、型、 品系等, 只有病毒还沒有为大家所公訩的林 奈式的分类系統 ${ }^{[1]}$ 。

微生物的分类一般都是按照以形态特征 为主, 生理、生物化学特性和生态条件为輔 的原則来划分的。只有少数类韋, 特別是具 有特殊功能的細菌, 如光能合成和化学能合 成的自养菌、醋酸菌、乳酸菌等才主要是以 其生理特性来規定的。形态特征除了包括結 构外, 也包括大部分的培养特征, 因作微生 物分类时, 时常必須进行微生物的培养, 而 在細菌分类中培养特征是一类主要的指征。

\section{一 形态特征是否是最好的分类指征}

按形态分类最为方便, 且一目了然, 所 以一般在进行分类时, 总喜欢把形态特征放 在首要地位。

从細菌分类学发展史来看, 就有以Cohn 和 Koch 为代表的单形論派和 Naegeli、Zopf、
Löhnis、Enderlein 等先后倡导的多形論或变 形論派之間的长期爭論 ${ }^{[2]}$ 。前一派訩为細菌 的形态是固定的, 郎使略有变更, 只要在正 常条件恢复时还会复原。后一派䚯为細菌的 形态是变化多端的，时常有极其复杂的发育 循环史，而且变幻莫測。显然，以上两种說 法都是违反进化諭的。現代絕大部分分类学 家都承訩生物在一定的历史时期，形态是相 对稳定的，而且应从每一种生物发育循环史 的基础上来了解它的形态，通常并不很复 杂。在分类上以形态为主, 在絕大多数情况 下是可以令人滿意的。多年来的研究証明, 形态、构造和功能是有一定的关系的，一般 承䚯形态可以反映生物的本貭。Красильни$\mathrm{KOB}^{[3]}$ 从生物进化上訩为, 外界条件的改变 首先引起生理上的变异，生理改变导致結构 的改变, 結构的改变最后才引起形态的改 变, 因此形态是比較稳定的特征。事实上, 形态特征通常也是不易变异的特征。

但是形态上表面的相似有时会引人誤入 迷途。例如，在 1927 年有一位德国的皮肤 病医生 Benedek, 曾把在人体上发現的巨大芽 孢杆菌 (Bac. megatherium) 誤䚯为是一种新 的裂殖酵母，命名为人型裂殖酵母 (Schizosaccharomyces hominis)。幸而在三年后，另 一位微生物学家 Dorrepaal 根据原始培养的 
显微检查指出了这一錯誤 ${ }^{[4]}$ 。因此必須指出, 只有能够表現本貭的形态特征，才是可靠而 重要的分类指征。

\section{二 各种分类指征都按等級排列是否合理}

一般微生物分类指征都有等級的差别。 传統的分类, 都是根据比較少数的指征, 按 等級划分各級分类单位。在一类机体中分 布最广或最常見的特征, 一般用以区別比㜞 大的分类单位, 如科、目等。只有少数微 生物所共有的特征, 則用以規定較小的分类 单位, 如种、属等。但是 Adanson 派分 类学家持有不同的意見 ${ }^{[3]}$ 。Adanson 是 18 世紀的一位法国軟体动物学家，他在 1757 年进行貝壳分类时提出两个分类原則：1. 必 須按照最大多数的特征进行分类；2. 不能預 先决定那些特征更为重要。最初由于对于 微生物特征䚯識得不够, 而以后料虽逐漸 丰富，但又感到整理困难，因此一直等到电 子計算机发明以后，所謂“計数分类学” (numerical taxonomy) 才得到迅速发展。 Sneath ${ }^{[5]}$ 提出他們这一派的分类原則是: 1 . 理想的自然分类系統是以尽可能多的特征为 根据的，其中的分类单位含有最多的“情 报”; 2. 在构成“自然的”分类单位时，任一 特征都是同等重要的；3. 全面相似性(overall similarity)或近似性(affinity)决定于共同特征 的比例； 4. 不同的分类单位是以相关的特征 为根据的； 5 . 近似性是和系統发育不同的。 为此, Sneath 䚲为, 使用 $40-50$ 个特征最 好有几百个特征才能得出接近实际情况的結 果。若計算相似性(Similarity), 通常按 Sneath 的下列忽式进行 ${ }^{[6]}$ :

$$
S=n s / n s+n d
$$

$n s,=$ 各株所共有的阳性特征的数目; $n d=$ 为一株所有而为另一株所无的特 征的数目。

另外, 这一派的 Cowan ${ }^{[7]}$ 否訩現存的微 生物种，他把希望完全寄托在細胞学、生物 化学以及遺传学等方面的研究上, 訩为現在 試图进行微生物分类是浪費时間。

我們覚得, “預先”就根据少数的特征来 进行分类是人为的分类, 例如按体积大小和 顏色排列图书是不科学的, 必須在找出主要 的指征和次要的指征之后才能进行分类。所 以我們不同意現代 Adanson 派“在构成”自 然的”分类单位时，任一特征都是同等重 要的”这一提法。只能說, 現在微生物的分 类还远非完善, 尤其种的范围还很难确定。 我們也不同意訩为目前进行微生物分类是浪 費时間的說法。微生物分类学也和其他的学 科一样, 需要一个发展的过程, 必須付出大 量的劳动才能日傣完善。

用电子計算机統計的方法找出生物之間 的异同，也就是它們之間的关系，可以說是 現代分类研究的新途径。不过应該注意，如 果按照任何特征都是同等重要的原則, 不加 㥀重考虑就任意提供材料，只要其多而不选 其精, 就很可能得出非常混乱而无法分析的 結果。我們随时都应想到，微生物分类已有 百年的历史, 已經积累了相当丰富的經驗。 例如細菌中早已找出真細菌、放綫菌、粘細 菌、螺旋体等相当自然的类堡，每个类萑都 是由少数主要的特征規定的, 必須尽量利用 这些宝貴經驗，而絕不能說它們的各种分类 指征都是同等重要的。

\section{三 关于种的概念}

一般訩为种是生物分类的基本单位，可 是大家对于种的概念和許多具体的种的䚯識 
都很不一致。大多数微生物学家承訩种是实 际存在的，但也有人 ${ }^{[7]}$ 訩为，只有个体是实 际存在的，而所有分类单位都是假想虛构 的, 只在分类学家的想象中存在着。这样的 看法其实是否䚯进化論的基本概念，同时也 过低地估計了人的理性訩識。因为通过对于 无数个体的了解, 就能知道某些个体基本上 是相同的，它們可以构成一个种，例如巨大 芽孢杆菌和向日葵同样是实际存在的种。虽 然，絕不否䚯，我們关于許多微生物种的概 念直到現在还相当 糢糊，而且有时 是錯誤 的，但总不能說某一微生物个体可以不属于 一定的种, 而只能承䚯我們对于它所属的种 还了解得不够清楚。

一般訩为, 种是由来源相同且彼此相似 的个体組成的，种与种間还必須有由于自然 选择或自然淘汰所造成的間断，而我們关于 种的概念是否正确要以是否符合实际情况来 决定。种既然包括很多个体而各組个体之間 必然多少会有一些差异，所以每个种都应有 必要的指征和可以容許的变化范围，而很难 由某一个体来代表。因此, ·在微生物特別是 細菌分类中，标准株或模式培养的广泛应用 就不是沒有缺点的。以一株菌代表一个种固 然可以使人对于这个种有一个很明确的概 念，但同时也把这个种的范围限制到最小的 限度。以根据少数菌株或甚至一株菌形成的 种的概念, 来衡量在自然界存在的相近似的 大量个体，必然会发現許多所謂非正常型， 这是細菌分类工作者經常遇到的困难之一。

关于种的范围各家看法不同。例如在放 綫菌分类学家中就有大种派 (lumpers) 和 細 分派 (splitters) ${ }^{[8]}$ 之分。大种派一般䚯为形态 和培养特征大体相似的菌株都属于同一种。 有一些菌株也可根据較小的差別再分为亚种 或变种或型(forma)。細分派則把种的范围看 的很小，在某一方面有显著不同就另立新 种。結果某一类拏研究的越多, 建立的种也 就越多。研究的株数越多, 自然它們所代表 的种就会越多; 但发現真正新种的实例一般 要比把变种或类型提升为种的实例少得多。 我們覚得，在 “生物种” 还无法确定的情况 下，种的范围是可以暫时随着我們的需要而 可大可小的。例如在微生物区系調查中以采 用大种比較合适, 但在矽究拮抗菌的分类单 位和所产生的抗菌素的关系时，最好把种的 范围規定得小而明确, 才易得到預期的結果。

Winogradsky ${ }^{\left[{ }^{9}\right]}$ 曾建議, 不要再象 以往 那样, 継續描述时常引起爭論的数目越来越 多的細菌的属和种，而应建立适当数目的 “生物型” (biotypes)，然后把和某一生物型相 近似的类型放在它的周围。Waksman ${ }^{[10]}$ 进行 放綫菌分类时，一向主张建立种拏。Schaef-

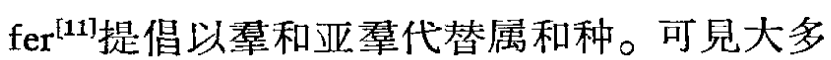
数微生物学家都有把种的概念放寬的傾向。 另一方面，Kauffmann ${ }^{[12]}$ 則建議在腸杆菌特 別是沙門氏杆菌的分类中, 以血清型代替种， 这就会把种的范围縮小。

許多人 ${ }^{[11]}$ 䚯为, 現在的細菌种还只是分 类鉴定的种, 需要进一步的研究才能建立所 謂生物种。我們㸴究微生物分类的目的，主 要是要对于这些微小的机体有明确䚯識, 以 便更有效地利用或防治它們。所以当前最重 要的問題是大家对于一些常自的种的䚯識要 基本一致，这样才会有共同的語言，才能彼 此互用所积累的資料。

我們关于种的概念是否正确，应以是否 符合实际情况为标准。通过多方面分类鉴定 实践的考驗，逐漸加以补充和修改，这样我 們关于种的概念必然会越来越接近真实。 


\section{四 細菌种的系統发育学說}

一般訩为，生物分类的最終目的在于找 出生物之間的亲緣关系。但有人訩为, 現在 存在的类型都是系統发育的頂端，不可能揭 露某一类型源自另一类型。这种看法对于許 多微生物来說未必是真实可信的，例如放綫 菌、原放綫菌和分枝杆菌彼此之間的关系就 非常密切，而且可用实驗变异的方法使它們 互相轉变 ${ }^{[3]}$ 。不过，自然进化的方向有时很 难确定，虽然一般所謂进化是由簡单到复 杂，但由复杂到簡单的所謂退化演变的可能 性也很大。必須指出, 目前, 我們只能对于 細菌的系統发育提出一些假說, 借以帮助我 們了解各萑微生物之間的关系。某些細菌如 螺旋体接近原生动物，貝氏硫細菌和粘細菌 接近兰藻, 已为大家所公䚯。

在生理方面, Lwoff 和 Knight ${ }^{[13]}$ 相链指 出細菌进化表現漸次失去合成的能力, 所以 营养要求不严格的机体是最原始的。专化类 型則代表进化的頂端，但来源不同的有机体 也可演化为相似的生理型。ОПарин 在 1960 年指出 ${ }^{[1+]}$ ，最初的机体是嫌气异养的，然后 出現光合作用的生物，最后才产生自养或异 养的好气类型。

在形态方面, Kluyver 和 van Niel 曾提出 最簡单的球菌是原始型,分別进化为螺菌、芽 孢杆菌和放綫菌。Stanier 和 van Niel ${ }^{[15]}$ 又对 这一学說加以修改和补充, 提出由球菌发出 四条进化綫：一条通向八迭球菌和芽狍八迭 球菌；一条經过假单狍菌和弧菌达到螺菌； 一条通过周生鞭毛菌达到芽抱杆菌; 一条通 过分枝杆菌和原放綫菌达到放綫 菌。Kpacrльников ${ }^{[3]}$ 則訩为放綫菌的演变是由放綫菌 通过原放綫菌到分枝杆菌和芽生球菌，然后
分两枝:一支从分枝杆菌到丙酸菌、乳酸菌和 拟杆菌; 另一支从芽生球菌到鏈球菌、細球 菌和八迭球菌。我們覚得，这样的看法不如 按球菌通过芽生球菌、分枝杆菌、原放綫菌 到放綫菌的路綫显得更为自然。

Bisset $^{[13]}$ 指出，細菌进化的整个趋势和 大部分生物进化是一致的, 郎从水生到陆 生。他否訩球菌是最原始的类型，因为它們 可能具有复杂的多胞結构。他还指出, 最原 始的細菌为水生、螺旋形、带极端鞭毛，以 及营养要求不严格等，它們有的能够进行不 同程度的光合作用或化学能合成作用。最进 化的类型是真杆菌、球菌或生枝菌絲（放 綫菌)。周毛菌能在潮湿的表面上游动，时 常具有能由空气传播的狍子, 許多比較进化 的細菌营养要求都相当严格，无一自养菌。 最成熟的陆生型大概是芽狍杆菌和鏈䨣菌。 某些鏈霜菌适应特殊的环境，演化为小单狍 菌。Bisset 又指出, 大部口腔寄生 細菌都是 退化型, 同时大部細菌由腐生变为寄生的过 程是：体积变小，形态变簡单，失去革兰氏 染色阳性的性能，失去某些酶系統（包括过 氧化氞酶)，最終寄生菌为嫌气、表 面 革兰 氏阴性、营养要求严格。真正革兰氏阴性細 菌是从螺菌通过假单孢菌、弧菌到变形杆菌 (Proteus), 后者是高度进化的类型。

\section{五 細菌在微生物界的位置}

根据近年来关于微生物的細微結构和精 密化学分析，对于各类微生物之間的关系和 彼此的区別及有了进一步的訩識 $[4,16,17]$ 。

（1）細胞微生物和非細胞微生物

病毒构造比較簡单，沒有一般所謂細胞 的結构，所以可称为非細胞微生物。签菌体 自然应包括在病毒之內。細菌和其他微生物 
都有細胞結构，可統称为細胞微生物。

按照 Lwoff ${ }^{[18]}$ 对于病毒所下的定义，可 以看出这类超微生物和細菌的基本区別。病 毒只含有一种核酸 (DNA 或 RNA), 以核酸 的形式在寄吉細胞內复制繁殖，不分裂; 进 入寄主細胞內的病毒侵染小体沒有产生提供 能量的三磷酸腺草 (ATP) 的酶系統。細 菌 是有細胞的机体，含有两 种核酸（DNA 和 RNA），一般依賴于分裂而繁殖，具有产生 ATP 的酶系統。因此 Stanier 等 ${ }^{[4,16]}$ 訩为細菌 和病毒之間是有明确的界限的。他們指出， 立克次氏体以及砂眼、婴鳥武热和淋巴肉芽肿 的病原体都是广义的細菌而非真正的病毒。

（2）原核微生物和輿核微生物

19 世紀末叶微生物学家們就㲘指出, 真 菌有明显的細胞核, 而細菌的核則很不明显。 后来逐漸訓識細菌和兰藻的細胞核比較簡 单。Chatton 1937 年就筸建議称这类生物为 原核生物(Procaryotes)。䀰菌、高等藻类、原 生动物和高等动植物有比較完 善的 細胞核, 称真核生物 (Eucaryotes)。最近 Stanier 等 ${ }^{[4,16]}$ 根据細胞学的新資料对于这两类細胞的結构 与功能作了进一步的探討。

总的看来，真核細胞的細胞核和細胞 器, 如綫粒体和叶綠体等都有外膜包着。而 原核細胞只有原生貭膜，而无細胞核膜; 細 胞器郎使有, 也比較簡单, 且无外膜。据說 这是和固醇含量小相关联的。原核細胞的內 容物經常是靜止不动的，郎使偶有流动，范 围也很小，核区与非核区总不混淆，䞳核細 胞的原生稹則經常流动, 核和細胞器时常移 动。Stanier 等訩为, 真核細胞內容物呈溶胶 状态，原核細胞內容物呈凝胶状态。我們 訩为, 这样的說法也許过于簡化了一些。

原核細胞內确实有机能和化学成分都不
同的各个区域，例如核区是和原生貭区是明 显分开的。核区充满細絲至少部分是由 DNA 的长分子构成的。細菌生长期，核分裂先于 細胞分裂，因此細胞时常是多核的。至于原 生稹內, 含有核酸蛋白体 (ribosomes) 的成分 是清楚的，郎由 RNA 和蛋白稹构成。在 細 菌內倘末发現与蛋白稹結合的 DNA，这也 是与冝核細胞不同的。原核分裂只是染色稹 体的簡单分裂，并无有絲分裂現象。根据現 有少数資料，原核細胞染色体数目很小。例 如大腸杆菌, 按照 Wollman 和 Jacob ${ }^{[19]}$ 的遺 传学分析，只有一个染色体，本时呈环形， 遺传因子呈綫形排列在上面。染色体可断开 呈綫状，交配时可进入雌細胞 $\left(\mathrm{F}^{-}\right)$內，时 常只部分进入而传递部分遺传因子，逐使雌 細胞变成不完全接合子（merozygotes）。但 Delamater ${ }^{[20]}$, 根据核染色和电子显微鏡覌察， 則訩为大腸杆菌有 3 个染色体，一长两短。 現在电子显微技术不但还不能够洞察細菌染 色体的构造, 而且也不能确切表明染色体的 数目。所以我㑚宁愿相信“遺传学是一种銳利 的解剖工具”[21] 这一說法, 而暫訩为大腸杆 菌只有一个染色体。細菌的营养細胞是单倍 体，只有不完全接合子是双倍体; 大部冝核 細胞則都是双倍体，只有配子是单倍体，这 是原核細胞与椇核細胞的另一区別。

真核細胞的呼吸作用是和綫粒体相关联 着的。綫粒体含有三羧循环的酶系統和与氧 联系的电子传递系統，以及合成 ATP 的酶 系統。綫粒体有双重膜, 从內頁长出綫粒体 冠或称崝突，区分为几个小間。保証电子传 递的酶就在崎突內。原核細胞如巨大芽狍杆 菌和藤黄八迭球菌: 其呼吸部位好象就在原 生盾膜內，电子传递的酶系統完全在原生稹 膜內，大部分三羧循环的酶則分布在原生稹 
內。Fitz-James 等 ${ }^{[4,16]}$ 在革兰氏阳性細菌和放 綫菌的超薄切片內发現管状或圈春形的頁片 結构, 称間隙体或中頁体 (mesosomes), 訩为 是由原生貭膜內陷突长而成的，可能是呼吸 作用的中心，也可以把它們看做解形的綫粒 体。在革兰氏阴性細菌內向未发現間隙体。

圎核細胞如果具有光合作用的机能，就 是在叶綠体內进行。叶綠体含色素和电子传 递系統, 二者协調地把光能轉化为化学能。 叶綠体还含有整整一系列的酶类把二氧化碳 轉变为淀粉。典型的叶綠体外有双重膜, 中 含大量扁圓盘，每个扁圓盘似是双重頁片， 圓盘四周为均匀区，无細微結构，称为基稹。 在扁圆盘內部进行能量的轉化。生物合成的 酶可能在基稹內。原核細胞如兰藻的光合作 用也在原生稹所含的双重頁片內进行。这些 双重頁片相当于叶綠体的扁圓盘，只是沒有 外膜包着，頁片四周有未分化区，相当于叶 綠体的基稹。光合作用細菌的原生稹內有囊 状載色体 (chromatophores)，其作用相当于兰 藻的双重頁片。在一种紅螺菌一莫氏紅螺菌 (Rhodospirillum molischianum) 的原生盾內 发現少数頁片区很象兰藻或叶綠体的頁片。

真核細胞的呼吸和光合作用是在完全分 开的两种不同的細胞器內进行的; 在原核細 胞內这两种机能的关系比較密切, 在光合作 用細菌內这两种机能的电子传递系統可能是 依賴同样一些成分 (如細胞色素等) 进行的。 光照时常抑制呼吸。曾在紅蛿菌內发現呼吸 酶系統中的琥珀酸氧化酶位于載色体內。有

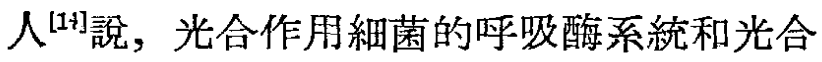
作用結构一起都位于載色体上。

兰藻和細菌都是由原核細胞构成的, 它 們之間的关系非常密切。就如貝氏硫細菌 -(Beggiatoa) 和絲硫細菌(Thiothrix) 簡直就可
称为无色素的兰藻。兰藻和細菌的区別主要 在光合色素方面，兰藻都含有叶綠素和藻兰 素，都能进行光合作用; 細菌絕大部分无此 机能。能够进行光合作用的綳菌所含的色委 也和兰藻不同 ${ }^{[17]}$, 为細菌叶綠素和脂族类胡 罗卜素或 1-2 种綠硫細菌叶綠素和单环类 胡罗卜素, 永无藻兰素。此外, 許多具細菌 都靠鞭毛进行运动，而兰藻只能滑行。

\section{六 細胞壁的結构和成分在微生物 特別是細菌分类中的甞义}

細胞壁的主要功能在于賦予細胞一定的 形状和強度, 使耐渗透压, 起保护作用。这 一点对于大部分都是单細胞和单行列細胞的 微生物特別重要。真核微生物的細胞賴䊹維 素、牛䊹維素、几丁貭或硅化物等物貭保証 細胞壁具有一定的強度。細菌細胞壁則沒有 上述各类物稹, 它的坚固性是由另一类粘肽 化合物賦予的。粘肽至少含 3-4 种基本氨 基酸和两种氨基糖，一般还有其他的氨基酸 和糖类，有时还有脂类。基本氨基酸是谷氨 酸、丙氨酸和二氨庚二酸或賴氨酸，后两种 氨基酸很少㚏存。氨基糖是乙酰氨基葡萄糖 和乙酰膜酸（图 1)，膜酸或称氨基糖肽酸 ${ }^{[22]}$ 是带羧基的氨基葡萄糖(3-0-carboxyethyl- $D$ glucosamine）。一般膜酸的羧基与氨基酸分子 或短鏈相連（图 2)。

少数革兰氏阳性細菌的細胞壁几乎完全

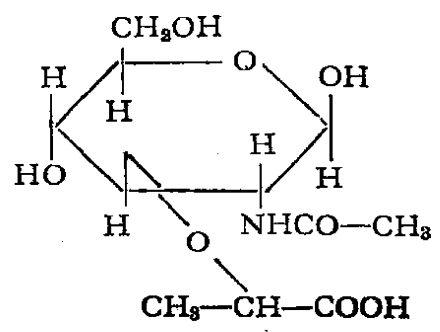

图 1 N-乙酰䠑酸 
是由上述粘肽构成的， 而大部阳性細菌除粘肽 外还有粘多糖，二者結 合构成粘复合体。有时

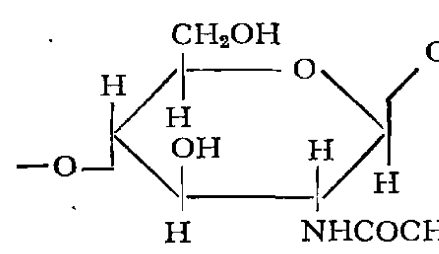

还有壁酸(teichoid acid)。

壁酸是磷酸甘油或磷酸 核醇的聚合物，其与膜 酸和氨基酸的連結方式 可参閱文献 $[23]$ 。主要 由粘肽构成的細胞壁可 能完全被溶菌酶所分 解，特別是氨基糖和膜酸的 1,4 鍵被破坏。 青雳素的作用与此不同，它是阻止把粘肽的 成份加到生长的細菌細胞壁內。革兰氏阴性 細菌的細胞壁也总含有粘肽, 但含量較阳性 細菌者少。阴性細菌細胞壁的結构和組分較 为复杂，含有相当多的脂类，且氨基酸种类 也比較多。Weidel 等 ${ }^{[4,16]}$ 曾仔細研究大腸杆 菌的細胞壁, 发現共有三层, 外两层分別为 脂蛋白和脂多糖，內层为由粘肽鏈連結着的 蛋白稹。

細菌、放綫菌和立克次氏体的細胞壁都 含有粘复合体。兰藻的細胞壁,根据 Salton ${ }^{[16]}$ 的資料，所含組分很象革兰氏阳性細菌。粘 細菌 (含相当多的二氨庚二酸)、螺旋体以

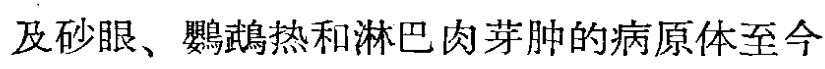
佾无細胞壁成分的分析資料，但根据它們都 对青霜素敏感推測大概都含有粘复合体。此 外，在悬核細胞內从未发現粘肤。

二氨庚二酸只在原核細胞壁內发現，是 其特有的成分。但有些細菌如球菌和乳酸菌 以及嫌气寄生的放綫菌等，就沒有这种氨基 酸，它为賴氨酸所代替，因此大家訩为膜酸 是粘肽的最好的指示成分。

根据 Salton ${ }^{[24]}$ 的报导，一向把細菌分为

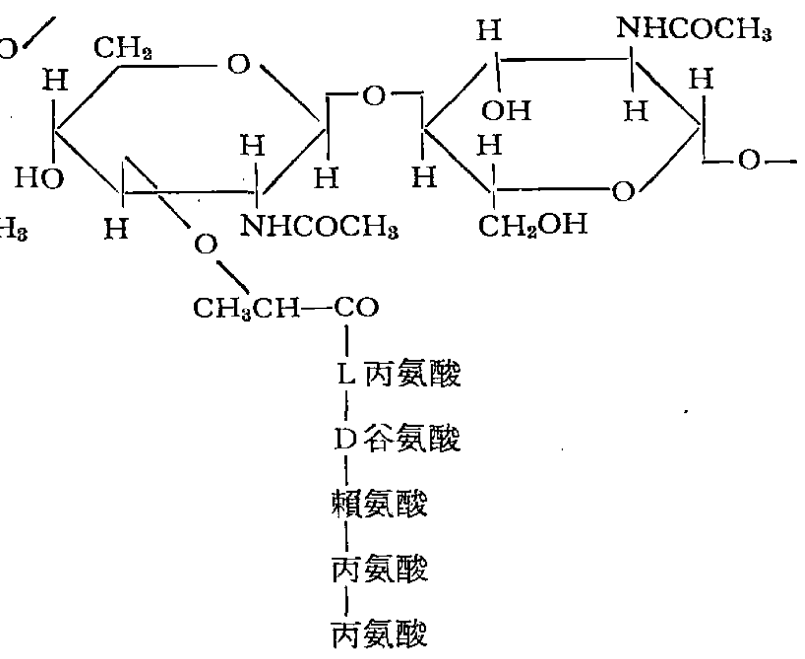

图 2 粘肽的一部分

两大类的革兰氏染色是阳性还是阴性也主要 决定于細胞壁的結构和組分。碘結晶紫复合 体对于阳性和阴性細菌的染色作用几乎相 同。但磑与阳性細菌細胞壁內多糖的 $\mathrm{OH}$ 基 結合，再用浓酒精脫色时，細胞壁的小孔郎 縮小，色素就不能漏出。阴性細菌則沒有这 一特点。曾有人用放射性 $\mathrm{P}^{32}$ 的化合物作出 了証明。因此当細胞壁的完整性遭到破环 时, 革兰氏阳性細菌就都变为革兰氏阴性了。 根据 Mitchell 和 Moyle ${ }^{[25]}$ 的估計, 細球菌、 藤黄八迭球菌和金黃色葡萄球菌的細胞壁小 孔直径約为 1 毫微米, 直径 2.5 毫微米的葡 萄糖胶分子郎不能进入。

L-型細菌是不能合成粘复合体的畸型 微生物，对于渗透压特別敏感。在自然界特 定的环境中也有不能合成完整粘复合体的微 生物，那就是胸膜肺炎类微生物，在 Bergey 細菌学鉴定手册第七版 ${ }^{[26]}$ 中列为裂殖菌綱的 一目一一枝原貭体目 (Mycoplasmatales)。

\section{七 运动器官和方式在細菌 分类中的意义 ${ }^{[16,27]}$}

細菌类有三种比較常見的运动方式，都 是目或綱的分类指征。 
（1）鞭毛划动 鞭毛是奥細菌所常有的 运动器官，它們的生长位置在真細菌的分类 中占很重要的地位。Bergey 手册 ${ }^{[26]}$ 中, 周生 鞭毛是㬈細菌目的特征，极生鞭毛为假管胞 菌或极毛杆菌目的特征。

細菌的鞭毛时常是由一根原䊹維构成 的，粗約 100-200 埃，无鞘膜包轺。生物 化学分析表明, 原䊹維属于角盾一肌球蛋白 組的比較䉍单的蛋白原。少数德細菌的鞭毛 是由 2-3 根很細的原䊹維螦撩交織而成的, 鞭毛从原生愿內的基粓长出，在某些单生极 毛的根部看得特別清楚。

細菌的鞭毛和某些臭核微生物如夏菌、 高等藻类以及原生动物的鞭毛和䊹毛的結构 是不同的。后一些运动器官是由 11 根原脬 維构成的， 2 根位于中央，其余 9 根环繞四 周。整个鞭毛由原生貭膜长出的鞘膜包着, 真核微生物的鞭毛长在基体上。基体与細菌 的基粒不阔。一根原䊹維的大小与細菌鞭毛 糿維大致相同。

(2) 軸絲伸縮 这是螺旋体目 ${ }^{[26]}$ 或䋃 ${ }^{[3]}$ 的运动方式。軸絲成螺旋地分在在蛁旋体表 面, 使螺旋们縮种旋轉而迅速前进。軸絲由 原糿維束构成，两端固定在細胞闪的基粒上。

(3) 滑行 这是粘細菌利貝氏硫細菌 目 ${ }^{[26]}$ 的运动方式，也是兰藻的运到方式。至 于这种运动的机制 ${ }^{[27]}$ ，有人説是由于表面张 力, 有人铞是由于渗透压力, 还有人訩为是 由于菌体曲什，説法很多。更多的人誩为和 粘液的分泌有关, Красильников ${ }^{[3]}$ 也說是由分 泌粘液时所发生的反冲作用而前进或侧行。 总之,这是一个需要进一步加以証明的䦐題。

除了以上三种运动方式外, Fauré-Freniet 等 ${ }^{[28]}$ 报导，大卯硫細菌 (Thiovolum majus)具 有特殊的运动器官。这是一种跃动很快的大
型无色硫細菌。电子显微鏡观察表明，在原 生稹膜內有彼此本行的原䊹維束，长达 0.3 微米，原䊹維直径 100 埃; 一端与原生稹膜 內面相連，另一端与一基膜相連，这可能是 使这种細菌活泼跃动的器宫。

某些買核微生物邚变形虫、粘菌等，有 时原生稹不为僵硬細胞壁所約束，可进行阿 米巴运动，而原核微生物还沒有发現能这样 地运动。这大概是由于原核細胞时常呈靜止 不动的凝胶状态的緣故。

\section{八 微生物特別是細菌分类学 的发展前景}

現代微生物分类学已不能局限于形态、 培养特征和簡单生理特性的描述，而要設法 利用所有可以利用的多方面的資料来充实分 类学。否則就不能碓定細菌种，从而闇明各 种堡或各个种之間的系統发南上的关系。

根据发酵能力和某一代謝途径的有无， 可把各譬細菌分为不同的組，也可确定一些 属和种 ${ }^{[29]}$ 。例如筆性好气的气芽孢杆菌 ( Aerobacillus) 能够发酵葡葡糖, 而絕对好气的 芽狍杆菌 (Bacillus) 一般沒有这种能力。 这两属之間的关系何萧性好气的气极毛菌 (Aeromonas) 和极毛杆菌(Pseudomonas)之間 的关系相问。

免疫血清学的分析是各类細菌分型分种 的常用的方法，也时常用筑菌体分型。例如 Kauffmann ${ }^{[12]}$ 对于腸杆菌科进行分类时就建 議用生化特性建立属，以血清型代替种，发 亚型和筑菌体型則相当于亚种。

代謝产物的分析早已广泛地应用到細菌 分类中来, 例如早就应用于乳酸菌、丙酸 菌、丁酸菌等类峟。抗菌素的产生在現代拮 抗性放綫菌分类学中占据着重要的地位，已 
經应用的有抗菌譜的測定、放綫菌相互拮 抗、抗菌素紙层析、对抗菌素的敏感性等多 种分类方法 ${ }^{[30]}$ 。

关于新技术的应用，除用电子显微鏡广 泛覌察放綫菌的表面結构 ${ }^{[31]}$ ，以期找到确定 某些种的补充根据外，目的也在于用到分类 中的細菌菌体紅外綫吸收光譜的研究也已展 开。Arai 等 ${ }^{[32]}$ 已用这一方法証实諾卡氏菌是 分枝杆菌和鏈雺菌的中間型。

遺传学对于微生物特別是細菌的分类学 已有很多的貢献 ${ }^{[11,21,33,3 t]}$ 。通过杂交、轉变和 轉导的方式，在沙門氏杆菌的血清型之間、 㖺血杆菌不同的“种”之間、肺炎双球菌和，
某些鏈球菌之間、大腸杆菌和志賀氏杆菌之 間、大腸杆菌和沙門氏杆菌之間、土壤杆菌 和根溜菌之間以及放綫菌中金需菌和紅霥菌 之間都曾实現了遺传重組，这至少可以进一 步証明这些細菌种或属之間的亲緣关系。随 着遺传学資料的积累, 将可考虑某些种、属 的調整，使之更有生物学的意义。

由于細菌細胞学的研究和化学成分的分 析, 已使这一学科逐漸达到細胞水平和分子 水本。Cummins 等 ${ }^{[35,36]}$ 在放綫菌細胞壁組分 的分析方面，成績尤为突出，他們为各属的 区分找到了化学的依据 (表 1)，并根据这些 資料对于某些种、属提出了調整的建議。例

表 1 各属放綫菌細胞壁的主要組分 ${ }^{[86]}$

\begin{tabular}{|c|c|c|c|c|}
\hline \multirow{2}{*}{ 对氧的需要 } & \multirow{2}{*}{ 属 种 名 称 } & \multicolumn{3}{|c|}{ 細胞壁主要組分 } \\
\hline & & 糖 & 氮 基 酸 & 氨 基 煒 \\
\hline 微量好气或嬚气 & $\begin{array}{l}\text { Streptomyces } \\
\text { Nocardia } \\
\text { Actinomyces israeli } \\
\text { Act. bovis }\end{array}$ & 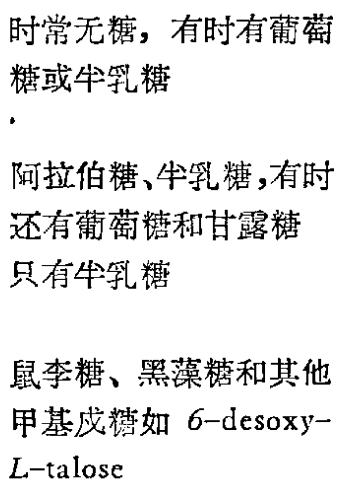 & 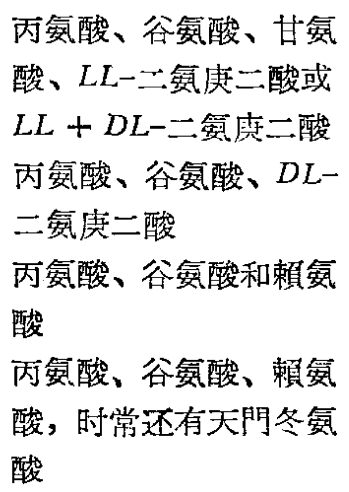 & $\begin{array}{l}\text { 总有氨基葡萄糖和膜酸， } \\
\text { 有时还有氨基本乳糖 }\end{array}$ \\
\hline
\end{tabular}

如白乐杰諾卡氏菌(Nocardia pelletieri) 本来 分类位置就很难明确, 有人誩为是諾卡氏 菌，有人訩为是鏈薷菌。經 Cummins 等分 析，3株这种菌的細胞壁，都沒有諾卡氏菌 之特征的阿拉伯糖，而有鏈䨰菌的 4 种氨基 酸。因此这个种无疑属于鏈䨠菌。果然在 Waksman 1953 年的专論 ${ }^{[37]}$ 里这个种少 属于 諾卡氏菌，而在 1961 年的专諭 ${ }^{[10]}$ 里就属于 鏈震菌了。

还有一些关于核酸的研究已可用于細菌
分类，至少已为細菌分类的深入研究展开了 一个引人注目的前景。Vendrely ${ }^{[38]}$ 曾指出, DNA 內腺嘌呤十胸腺嘧啶和鳥便嘌哈 + 胞 核嘧啶的比值在細菌分类中可表明种的区 別。一般在細菌内, 其比値范围为 $0.38-2.7$, 例如 Micrococcus pyogenes 的比值为 2.26 , 而 M. lysodeikticus 仅为 0.39 。Белозерский 等[39] 指出，核酸特异性組成的系統研究証明核酸 組成有一定的分类意义。細菌中DNA比RNA 变化更大。DNA 組成的特异性差別在某种程 
度上反映細菌的种如何划分为科和属。RNA 的微小差別可以作为把細菌分为更大的类檴 的指征。核酸成分特別是 DNA 和 RNA 內 核葉酸排列次序的进一步研究, 将有助于闀 明各个种的亲緣关系和建立进化系統。

最后必須強調指出, 細菌分类学必須在 传統分类学的基础上才能正常发展。物理化 学的渗唀和新技术的应用虽可促使現代細菌 学的迅速发展, 可使經典分类学逐漸深入和 更加合理化，但决不能代替分类学。現在有 許多发展比較快的学科, 如生理学、生物化 学、遺传学等时常使用微生物作研究材料。 可以期望，它們的研究結果对发展微生物学 特別是微生物分类学会有很大的推动作用。

[1] Pirie N. W., Prerequisites for virus classification, Microbial Classification, 12th Symposium of the Society for General Microbiology, University Press, p. 374-393, 1962.

[2] Winogradsky S. 《土壊微生物学》, 閻逊初翋, 科学 出版邧，1962。

[3] Красильников H. А., 《細菌和放綫菌的鉴定》, 䦎逊初譯,科学出版社, 1957。

[4] Stanier R. Y., Ann. Inst. Pasteur, 101, 297312 (1961).

[5] Sneath P. H., Microbial Classification, p. 289332, 1962.

[6] Bojalil L. F. \& Cerbón J., J. Bact., 81, 338345 (1961).

[ $;$ ] Cowan S. T., Microbial Classification, p. 433-455, 1962.

[8] Gottlieb D., Intern. Bull. Bact. Nom. Tax., 9, $13-14$ (1959).

[9] Winogradsky S., Ann. Inst. Pastcur, 82, 125 -131 (1952).

[10] Waksman S., The actinomycetes vol. II London, Baillère, Tindall \& Cox, LTd, 1961.

[11] Schaeffer P., Ann. Inst. Pasteur, 94, 167-178, (1958).

[12] Kauffmann F., lnt. Bull. Bact. Nom. Tax., 9, 1-6 (1959).

[13] Bisset K. A., Microbial Classification, p. 361$373,1962$.

[14] Гелман Н. С. и Лукоянова М. А., Микро- биология, 31, 556-569 (1962).

[15] Stanier R. Y. \& van Niel C. B., J. Bact., 42, 437-466 (1941).

[16] Stanier R. Y. \& van Niel C. B., Arch. Microbiol., 42, 17-35 (1962).

[17] Murray R. G. E., Microbial Classification, p. 119-144, 1962.

[18] Lwoff, A., J. Gen. Microbiol., 17, 239-253 (1957).

[19] Wollman E. L. \& Jacob F., La sexualité des bactéries, Paris, Masson éd., 1959.

[20] Delamater E. D., Bacterial Anatomy. The 6th Symp. Soc. Gen. Microbiol., p. 215-260, 1956.

[21] 盛祖嘉, 《微生物学进展》, 高侣蔭主編, 武汉大学出 版，p. 103-117，1963.

[22] Drews G., Naturw. Rdsch., 11, 425-431 (1962).

[23] Rogers H. J., j. Gen. Microbiol., 32, 19-24 (1963).

[24] Salton M. R. J., J. Gen. Microbiol., 30, 223235 (1963).

[25] Mitchell P. Ф., Moyle, J., Bacterial Anatomy, Univ. Press, p. 150-180, 1956.

[26] Bergey's manual of determinative bacteriology, 7th ed., 1957.

[27] Weibull C., Movement, The Bacteria, vol. 1, Structure, Acad. Press, p. 153-205, 1960.

[28] Murray R. G. E., The Bacteria, vol. 1, Structure, Acad. Press, p. 35-96, 1960.

[29] De Ley J., Microbial Classification, p. 164-195, 1962.

[30] 閣逊初, 微生物学报, 2, 139-144； 188-193; $227-240$ (1960)。

[31] 閐逊初, 《微生物学进展》, 高纷蔭主編,武汉大学出 版, p. 217-230, 1963。

[32] Arai T., Kuroda S. \& Koyama Y., J. Gen. Appl. Microbiol., 9, 119-136 (1963).

[33] Roper J. A., Microbial Classification, p. 270288, 1962.

[34] 刘颐屏,金震菌和紅雼菌的杂交育种,中国微生物学 会 1963 年年会学术会竔宣讀的諭交报告。

[35] Cummins C. S. \& Harris H., J. Gen. Microbiol., 18, 173-189 (1958).

[36] Cummins C. S., Ann. Inst. Pasteur, 103, 385391 (1962).

[37] Waksman S. A. \& Lechevalier H. A., 《放綫菌 及其抗生素分类鉴定指南》,閻逊初譯,科学出版社, 1958 。

[38] Vendrely R., Ann. Inst. Pasteur, 94, 142-166 (1958).

[39] Белозерский А. Н. и Спирин А. С., Исвестия AH CCCP, 1, 64-81 (1960). 